S sciendo

DOI: 10.2478/RAE-2019-0038 Review of Artistic Education no. 182019 341-346

\title{
8. THE TECHNIQUE OF OPTIMAL USE OF FACIAL MUSCLES IN TRUMPET INTERPRETATION
}

\author{
Iulian Horez ${ }^{315}$
}

\begin{abstract}
Facial muscles have an overwhelming importance in obtaining a special sonority, a perfect instrumental technique. In fact, through their vibration all sonority is produced by these muscles, and the level of professionalism one can reach depends on their degree of efficient use. We shall next analyze the specific issues and modality of use. While playing a mouthpiece instrument, due to the way facial muscle s are used, the following issues arise: exaggerated facial muscles stretching, clamping, undue strain, vibration limitation (by overpressing, outer reason).
\end{abstract}

Key words: trumpet interpretive technique, way of using facial muscles

\section{Exaggerated facial muscles stretching}

The extent of facial muscles stretching in the resting position is the same as that as while playing the instrument. A muscle stretch, however small, used from the first note issued, increases as we go up in the acute register. The use of this horizontal stretching movement greatly reduces the muscles vibration level. The larger the stretch, the greater the vibration stopping. This produces a totally low quality sound of the instrument (metallic, narrow), and besides this bad sonority, at higher intervals of thirds, fifths, there is a different stretch for each note, a fluctuating movement of the muscles on a horizontal plane. In case of a technical passage with small values of notes at longer intervals of fifths/sixths, this movement of the muscles can no longer be synchronized with the speed of notes, which inherently leads to imprecision on notes, failures etc.

This is a common defect not only for students, but also for professionals, because it seems like an easy, convenient solution in solving instrumental technique problems, but unfortunately it is a misleading solution that produces a limitation in sonority and instrumental technique. This way one will achieve a certain level of technique and instrumental sonority, which cannot be overcome. Only to maintain it, one will need a lot of individual study. The correct position in this case is the use of facial muscles without any stretching, exactly at the stretch they have, in the resting state. When using the mouthpiece to play, only the external parts of the muscles on the mouthpiece shall strain and just so as not to let the air out. A greater strain of the side facial muscles on the mouthpiece will lead to a change of sound.

\footnotetext{
${ }^{315}$ Associate Professor PhD., "George Enescu” National University of Arts from Iaşi of Romania, email: horez.iulian@yahoo.com
} 
Another common issue that may arise or may exist even from the beginning and for hereditary reasons is that of muscle swaying, or, in other words, the lower jaw is behind the upper jaw. The upper and lower jaws must be on the same vertical line. Most people, however, are born with the lower jaw slightly behind the upper one, and many teachers do not take into account this vertical difference between the two jaws, considering it totally irrelevant and when the pupil or the student cannot play in the acute register of the brass instrument, respectively, do not realize that this vertical synchronization between the two jaws is the main reason for this problem. The secondary may be excessive clamping, stretching or strain of muscles.

A great deal of attention should be paid to resolving this vertical symmetry between the two jaws and, implicitly, the two facial muscles. Nonsolving this verticality causes the air column to clog, as we go higher the instrument's acute register. Due to pressing which increases while advancing into the instrument's acute register, the lower jaw is pushed back, while the upper one is fixed. The more it pushes back, the lower facial muscles will move in the same direction, defending the vertical gap between the two facial muscles.

All of these changes are also added to the fact that, once in the acute register, the exit of the air column decreases vertically to obtain notes of higher sound frequency. The two changes, the first abnormal as a motion (the migration of the lower jaw inwards) and the second, naturally occurring in the acute register, lead to strangulation of the air column and implicitly the inability to play in the acute register, producing sound narrowing, reaching until its complete disappearance.

A lot of instrumentalists struggle with this deficiency, the inability to play in the acute and super-acute register of that instrument, and they do not realize the reason. The lack of this vertical symmetry of the two facial muscles is the most common defect in those who play a brass instrument. There are very few who have this native vertical symmetry, the teacher is the one proving his mastery to intervene as if there is no vertical symmetry of the two facial muscles to correct. The solution is to push the lower jaw outward until a perfect vertical plane is reached between the two. Once this verticality of the two jaws has been reached, it must not be changed at all over the entire length of the instrument, respectively from the low register to the super-acute, the ratio of verticality must remain the same.

By pushing the lower jaw forward, the instrumentist will feel a pain in the connection muscles between the two jaws, which will disappear in a relatively short time, all this vertical position change becoming reflex after a relatively short time. The lack of this verticality can be noticed if after a longer individual study time (one - two hours), due to the pressing carried out by the mouthpiece on the muscles (which must be as reduced as possible), a perfect circle shall remain impregnated for a short period of time (about 5-10 seconds), indicating the place where the mouthpiece rests on the two facial muscles. If this circle is 
equally visible on both the upper and lower muscles, this proves that the verticality of the two jaws is good, the pressing being equal to both upper and lower muscles, and the task of entering the vibration is equally distributed between the two muscles.

If only a semicircle appears on the upper muscle and the lower one is nonexistent, this shows that $80-90 \%$ of the pressing is supported only by the upper muscles, the lower one being only "present" and in the vertical plane the lower jaw is not on the same vertical line with the upper jaw, being behind it, as viewed from the outside. The more one goes up in the acute register, this inward movement will continue, resulting in the strangulation of the air column and implicitly in the inability to play in the acute register.

The horizontal stretching of the muscles is exactly what should not be done to advance in instrumental technique, as the reduction of the air column outlet is made in a vertical plane and not horizontally through this stretch. The variation juggles in the diameter of this hole to be made in fractions of seconds can be made much easier in the vertical plane by approaching or spacing the two muscles than in the horizontal plane, which requires a much wider movement thereof. In fact, the movement to obtain different notes must be made only inside the mouthpiece and not outside it (which would greatly brake the development of instrumental technique), or the vertical movement towards the horizontal one is more difficult to obtain, it requires more time. However, once this vertical muscular movement inside the mouthpiece is controlled, great results in the instrumental technique shall be obtained, compared to the horizontal one, which allows technical-instrumental progress only at a certain level.

\section{Unjustified crispening, straining}

There is a big difference between crispening and straining facial muscles, as this is one of the mistakes made by the prospective instrumentalists and even by the professional ones. During trumpet or other brass instruments playing, facial muscles crispening should be absent and strain at the lowest level. When going to the acute register, muscles become more and more strained, because of pressing and air column pressure that grow directly proportional to the advancement towards the acute and super-acute register of that instrument. In this ascending movement, many people fall into the facial muscles crisping mistake, feeling they can play more easily in this register of the instrument. It is a misleading feeling, apparently very convenient, but without any future in technical-instrumental progress. The explanation lies in the fact that the two facial muscles do not allow them to vibrate to maximum parameters, resulting in a tough, narrow sonority while ascending in the acute register, narrowing even more.

The balance between the three factors mentioned above (pressing, breathing, tension) leads to outstanding results, to a permanent technical 
instrumental progress. Their imbalance produces a limitation or stagnation in instrumental technique, muscular crispening. Speaking of facial muscular tension, it must be at the limit of escaping the air out through the lateral sides in the horizontal plane of the mouthpiece. Facial muscles crispening occurs due to a pressing either exaggerated or too little present. But the wrong level of pressing is not the only one that causes the occurrence of these facial muscles crispening, another determining factor in its occurrence is the incorrect use of the air column. An air pressure under a certain technical passage at one time can immediately lead to a crispening of these muscles, a natural response to the body's compensation. For this reason, the instrumentist must have a permanent self-control over the factors that are producing a sound emission, a technical passage on that instrument. Any carelessness, negligence or indifference can lead to the occurrence of unexpected defects that in time can become reflexes very difficult to modify.

\section{Limitation in the vibration of the facial muscles through exaggerated pressing - outer reason}

The limitation in vibration of the two facial muscles may have two causes:

- A first cause is the crispening of these muscles and not just their strain within the required limits;

- The second reason for vibration limiting of the muscles is the amount of pressing/pressure exerted on them by the mouthpiece. This pressing is an external reason that determines the level of vibration of the facial muscles. This external reason (pressing) can determine to a great extent the quality of the sound emission as well as the technical-instrumental level at which it can be reached.

The most common mistake for pupils and students and characterizing the Romanian brass school is exaggerated pressing, its use more than necessary. American and German schools are among the best in the world, where from the very beginning of practicing a brass instrument special attention is paid to the level of pressing, which must be as low as possible. Unfortunately, in Romania this is almost not taken into account, especially in children who start studying an instrument. More than $90 \%$ of the sound quality, the level of instrumental technique one can reach depends on the level of pressing on the muscles.

The use of a level of pressing as low as possible leads to outstanding performances in sound and instrumental technique, but results hardly appear after years of individual study, but once attained, professional satisfaction is great, the sense of continuous progress is permanent. Instead, the use of exaggerated or fluctuating pressing leads to quick results in time by pupils or students, even spectacular after 3-4 years of study on an instrument, but after this qualitative "explosion" in such a short time, either a qualitative stagnation or a very slow technical-instrumental breakthrough appear, as well as a series of problems related to technical-instrumental qualities. This is what happens in 
Romanian brass school. Exaggerated pressing generates a whole chain of mistakes throughout the technical-instrumental progress.

\section{Modes of sound articulation}

The modes of sound articulation are the following: simple staccato, double staccato, triple staccato. A determining factor in sound quality is both the way of sound articulation and the quality of sound. Simple staccato is the basic articulation mode in getting music notes as well as the most used of all. Simple staccato is achieved only by touching the inner surface of the facial muscles with the tongue, thinking about the pronunciation of the syllable your or you. This touch has to be done in a fraction of a second, during which the air column outlet will be closed, here is the place where this touch will occur. I say "touch" because a little more powerful impact on the facial muscles would instantaneously lead to the occurrence of a rough articulation of the marks, when there is a horizontal movement of the mouthpiece, which would greatly inhibit the technical-instrumental progress. This type of brutal articulation of notes is characteristic for those in military orchestras. A sound must appear "out of nothing", the articulation of the note must not be audible, it must occur but at such a level that is not acoustically perceptible

Double staccato is achieved by using a simple articulation, followed by a second articulation with the pronunciation $A$, which is achieved by lifting the posterior tongue muscles in a very short time towards the Palatine vault. The two types of articulations must be made in fractions of a second, and careful attention should be paid to equality of time and sound intensity of the two. By means of a consequent individual study a very high equality and speed can be achieved.

Triple staccato is achieved by using two simple staccato articulations and one double staccato (tu-tu-ku) There are, however, two formulas of triple stacatto - tu-tu-ku and $t u-k u-t u$. The second, $t u-k u-t u$, was widely used until the $1950 \mathrm{~s}$, but practice showed that the formula $t u-t u-k u$ is superior to that of $t u-k u-$ $t u$, being much more balanced as sound, giving much greater precision on notes and advancing technical-instrumental issues.

\section{References}

1. Alsteens, Stijn, Spira, Freyda, Ainsworth, Maryan W., Metropolitan Museum of Art (New York, N.Y.), (2012) Dürer and beyond: Central European drawings in the Metropolitan Museum of Art, 1400-1700, New York: Metropolitan Museum of Art; New Haven

2. Baker, Theodore, Slonimsky, Nikolas, (1995) Dictionnaire biographique des musiciens, Edition Robert Laffont, Paris

3. Barclay, Robert, (1992) The Art of the Trumpet-Maker: The Materials, Tools, and Techniques of the Seventeenth and Eighteenth Centuries in Nuremberg, Oxford University Press 
4. Bowyer, Carolyn Susan, (2016) Echoes of the salpinx: the trumpet in ancient Greek culture, doctoral thesis, Royal Holloway, University of London

5. Burkhart, Raymond David, (2016) Brass Chamber Music in Lyceum and Chautauqua, Hardcover

6. Caruso, Carmine, (1979) Musical Calisthenics For Brass. New York: Carl Fischer, 7. Cârstea, Sergiu, (2014) Metode de studiu care au revoluționat stilul de interpretare la trompetă (20th Century), in: Artes Magazine vol. 14, Artes Publishing House, Iasi,

8. Dokschizer Timofei, (1990) Methode de trompette: systeme d'exercices complexes, A. Leduc, Paris

9. Franquin, Merri Jean Baptiste, (1908) Methode Complete de la Trompette, Enoch, Paris

10. Ioan Goia, Metodica studiului şi predării instrumentelor de suflat, "George Enescu" Iaşi Conservatory, 282 p. + XXII (anexa).

11. Hoch, James E., (1994) Semitic words in Egyptian texts of the New Kingdom and Third Intermediate Period, Princeton, New Jersey: Princeton University Press

12. Patrick Kersalé, (2003) Musiques traditionnelles du monde: communiquer ici, làbas et au delà..., Lugdivine, Lyon

13. Pia, Jonathan, (2913) La tromba nella trattatistica musicale del XVII secolo, Lul.com

14. Edward Tarr, (2000) Die Trompette, Ed. Schott

15. Marc Vignal, (1999) Dictionnaire de la musique, Edition Larousse-Bordas

\section{Web pages}

https://fr.wikipedia.org/wiki/Maurice_Andr\%C3\%A9

https://en.wikipedia.org/wiki/Arturo_Sandoval

https://fr.wikipedia.org/wiki/Guy_Touvron

https://www.ziuaconstanta.ro/stiri/social/seara-concertistica-cu-lucrari-de-rossini-

mozart-vivaldi-si-arriaga-4645.html

https://fr.wikipedia.org/wiki/Didgeridoo\#cite_note-PK124-2

https://en.wikipedia.org/wiki/Trumpet

https://fr.wikipedia.org/wiki/Adolf_Scherbaum

https://fr.wikipedia.org/wiki/Trompette,

New Grove Dictionary of Music (HTML) \New Grove Dictionary of Music Version html.zip $\backslash$

http://www.biblia-ortodoxa.ro/vechiul-testament/numerii-a-patra-carte-a-lui-moise/ https://de.wikisource.org/wiki/W\%C3\%B6chentliche_Nachrichten_und_Anmerkunge n_die_Musik_betreffend\#3._Jahrgang_(1768)

https://ro.wikipedia.org/wiki//Iosephus_Flavius, https://fr.wikipedia.org/wiki/Salpinx_(instrument)\#Sonorit\%C3\%A9

https://ro.wikipedia.org/wiki/Iosephus_Flavius

http://vladimirrosulescu-istorie.blogspot.com/2011/03/roma-arcul-de-triumf-al-luititus-forum.html

http:/oxfordindex.oup.com/view/10.1093/gmo/9781561592630.article.28530, https://www.encyclopediecanadienne.ca/fr/article/musiciens-ambulants/, https://www.hyperion-records.co.uk/dw.asp?dc=W5419_67266 